\title{
Prevalence of intestinal parasitic infections in Brazil: a systematic review
}

\author{
Ariel Oliveira Celestino ${ }^{[1]}$, Sarah Cristina Fontes Vieira ${ }^{[1],[2],}$ Pablo Amercio Silva Lima ${ }^{[2]}$, \\ Larissa Maria Cardoso Lima Rodrigues ${ }^{[2]}$, Isabel Ribeiro Santana Lopes ${ }^{[3]}$, \\ Camila Mendonça França ${ }^{[2]}$, Ikaro Daniel de Carvalho Barreto ${ }^{[4]}$ \\ and Ricardo Queiroz Gurge[ [1],[2]
}

\author{
[1]. Universidade Federal de Sergipe, Programa de Pós-Graduação em Ciências da Saúde, Aracaju, SE, Brasil. \\ [2]. Universidade Federal de Sergipe, Departamento de Medicina, Aracaju, SE, Brasil. \\ [3]. Universidade Federal de Sergipe, Departamento de Medicina, Campus Lagarto, Lagarto, SE, Brasil. \\ [4]. Universidade Federal Rural de Pernambuco, Programa de Pós-Graduação em Biometria e Estatística Aplicada, Recife, PE, Brasil.
}

\begin{abstract}
Introduction: Parasitic infections are considered a major public health problem due to their associated morbimortality and negative impact on physical and intellectual development, especially in the at-risk pediatric group. Periodic prophylactic administration of antiparasitic agents against soil-transmitted helminths is recommended by the World Health Organization (WHO) to control parasitic infections and disease burden. We aimed to evaluate the prevalence of intestinal parasitic infections in Brazil. Methods: We performed a systematic review by searching the literature found in the PubMed, LILACS, and SciELO databases, followed by a meta-analysis of the proportions from studies published in English, Portuguese, and/or Spanish from January 2000 to May 2018. This systematic review was registered in the PROSPERO database (CRD42018096214). Results: The prevalence of intestinal parasitic infections (protozoa and/or helminths) in Brazil was 46\% (confidence interval: 39-54\%), with 99\% heterogeneity. Prevalence varied by region: $37 \%, 51 \%, 50 \%, 58 \%$, and $41 \%$ in the Southeast, South, Northeast, North, and Central-West regions, respectively. Most studies (32/40) evaluated children $(<18$ years $)$ and found an average prevalence of $51 \%$. Children also had the highest prevalence in all four regions: Central-West (65\%), South (65\%), North (58\%), Northeast (53\%), and Southeast (37\%). However, most studies evaluated specific populations, which may have created selection bias. Presumably, this review of intestinal parasitic diseases in Brazil includes the most studies and the largest population ever considered. Conclusions: The prevalence of intestinal parasitic infections is high in Brazil, and anthelmintic drugs should be administered periodically as a prophylactic measure, as recommended by the WHO.
\end{abstract}

Keywords: Parasitic diseases. Health policy. Communicable diseases.

\section{INTRODUCTION}

Parasitic diseases are part of the neglected tropical disease group and are considered a major public health problem due to their burden of morbimortality in several population groups. In groups considered at risk, there is a greater burden from these disease ${ }^{1,2,3}$.

It is estimated that up to $36 \%$ of the world population suffers from some form of parasitosis and up to $55.3 \%$ of children, according

\footnotetext{
Corresponding author: Ariel Oliveira Celestino.

e-mail: biomedica.ariel@gmail.com

(D) https://orcid.org/0000-0003-3907-187X

Received 9 February 2021

Accepted 23 April 2021
}

to the World Health Organization (WHO) in $2016^{4}$. Common clinical manifestations include diarrhea, reduced absorption of micronutrients, abdominal pain, vomiting, and dehydration ${ }^{4}$. Depending on individual health status, such manifestations can occur with different levels of severity.

There is a clear association between socioenvironmental factors, such as inadequate sanitation and hygiene levels, and intestinal parasitic infections, as they can promote the ingestion of contaminated water and/or food. Unfortunately, these factors are common in Brazils.

As collecting and testing stool samples prior to treatment is expensive and impractical in many low-income contexts, the WHO recommends prophylactic administration of antiparasitic agents 
against soil-transmitted helminths for at-risk groups in areas with high prevalence of helminth infections (greater than 20\% annually or greater than $50 \%$ biannually $)^{4,6}$. A program of mass anti-helminthic drug (albendazole) administration has been performed by the Brazilian Ministry of Health (MOH) over the past few years; however, there are no published data on the prevalence of intestinal parasitic infections in large population samples from different regions of Brazil to evaluate the effectiveness of this type of anti-helminthic treatment and whether it should be used, and if so, how often.

It is estimated that the prevalence of intestinal parasitic infections in Brazil is high; however, the rates may be underestimated in clinical practice as not enough patients are tested and the tests themselves have low sensitivity and specificity. Although there have been some studies of specific populations such as children in daycare centers, orphanages, and schools; prisoners; indigenous individuals; residents of quilombos (ancient slave settlements); and people who scavenge from rubbish dumps, the representativeness of their data is questionable, as it is likely that the prevalence of parasitic infections is much higher in these groups ${ }^{1,7-12}$.

Our study aimed to evaluate the prevalence and characteristics of intestinal parasitic infections in Brazil in order to provide data that can help determine how often the WHO anti-parasitic strategy should be implemented.

\section{METHODS}

This systematic review of literature was registered in the PROSPERO (International Prospective Register of Systematic Reviews) database (registration code CRD42018096214; http://www.crd.york.ac.uk/PROSPERO). The aim of this study was to answer the research question, "What is the prevalence and characteristics of intestinal parasitic infections in Brazil?" We included cross-sectional observational studies in which the prevalence of intestinal parasitic infections in a Brazilian population was described. The inclusion criteria were observational studies that analyzed human stool samples; were written in Portuguese, English, and/or Spanish; were published between 2000 and 2018; and contained information about location (region, state, city), age, and the number of samples. Studies from which it was impossible to extract data regarding the prevalence of intestinal parasitic infections in Brazil, as well as studies that evaluated other biological samples (not stool), were also excluded.

A search of the literature was conducted using three databases - PubMed (MEDLINE [Medical Literature Analysis and Retrieval
System Online]), LILACS (Literatura Latino-Americana e do Caribe em Ciências da Saúde), and SciELO (Scientific Electronic Library Online) - in May 2018. The selection of the studies and data extraction were performed by four independent researchers following a predefined protocol, and any disagreements were resolved using a fifth investigator The extracted data included the intestinal parasitic infection prevalence, age of the individuals, region, and diagnostic method.

The search strategy used Medical Subject Headings (MeSH), Health Sciences Descriptors (DeCS), and Boolean operators (OR and AND), which were used to combine descriptors as shown in Table 1. Duplicate references were excluded. The LibreOffice program (The Document Foundation; Berlin, Germany) was used to create spreadsheets, select studies, and extract and describe data in absolute and percentage frequencies. R Software (version 3.6.1; The R Foundation; Vienna, Austria) was used to perform the metaanalysis using a generalized linear mixed model. The prevalence of intestinal parasitic infections by region was calculated using a $95 \%$ confidence interval (CI). A funnel plot was used to assess the risk of bias and the $\mathrm{I}^{2}$ index to assess the degree of heterogeneity.

\section{RESULTS}

A total of 5297 titles were initially identified: 3702 from LILACS, 1268 from PubMed, and 327 from SciELO. Of these, 1019 duplicates were removed. From the remaining 4278 studies, blood sample and molecular studies $(n=36)$ and non-human $(n=63)$, nonepidemiological $(n=40)$, and non-intestinal parasitic $(n=3830)$ studies were removed, leaving 309 studies. Of these, 34 were excluded after reading the abstract, and 235 after reading the full text, leaving 40 studies that met the study criteria and were included in the systematic review (Figure 1). The studies included samples from children, adolescents, adults, and older adults from the five Brazilian regions, and one reported results from two regions (North and Northeast) ${ }^{13}$ (Table 2). Among the selected studies, the most commonly used laboratory test for stool sample analysis was the spontaneous sedimentation method using the Hoffman-Pons-Janner (75\%) method, followed by the Kato-Katz technique (22.5\%), and the Faust and Cols $(20 \%)$ method, with some studies using only one of these methods and some using one of these methods in combination with another type of test.

In our review, the population sample was categorized by age groups of over and under 18 years of age. In 32 of the 40 studies $(80 \%)$, the population samples included individuals under 18 years of age. Sixteen studies provided additional information

TABLE 1. Search strategies by database.

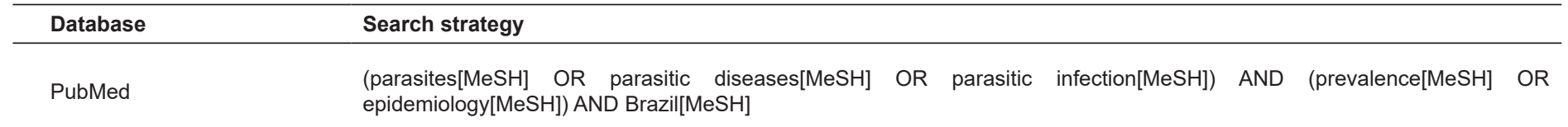




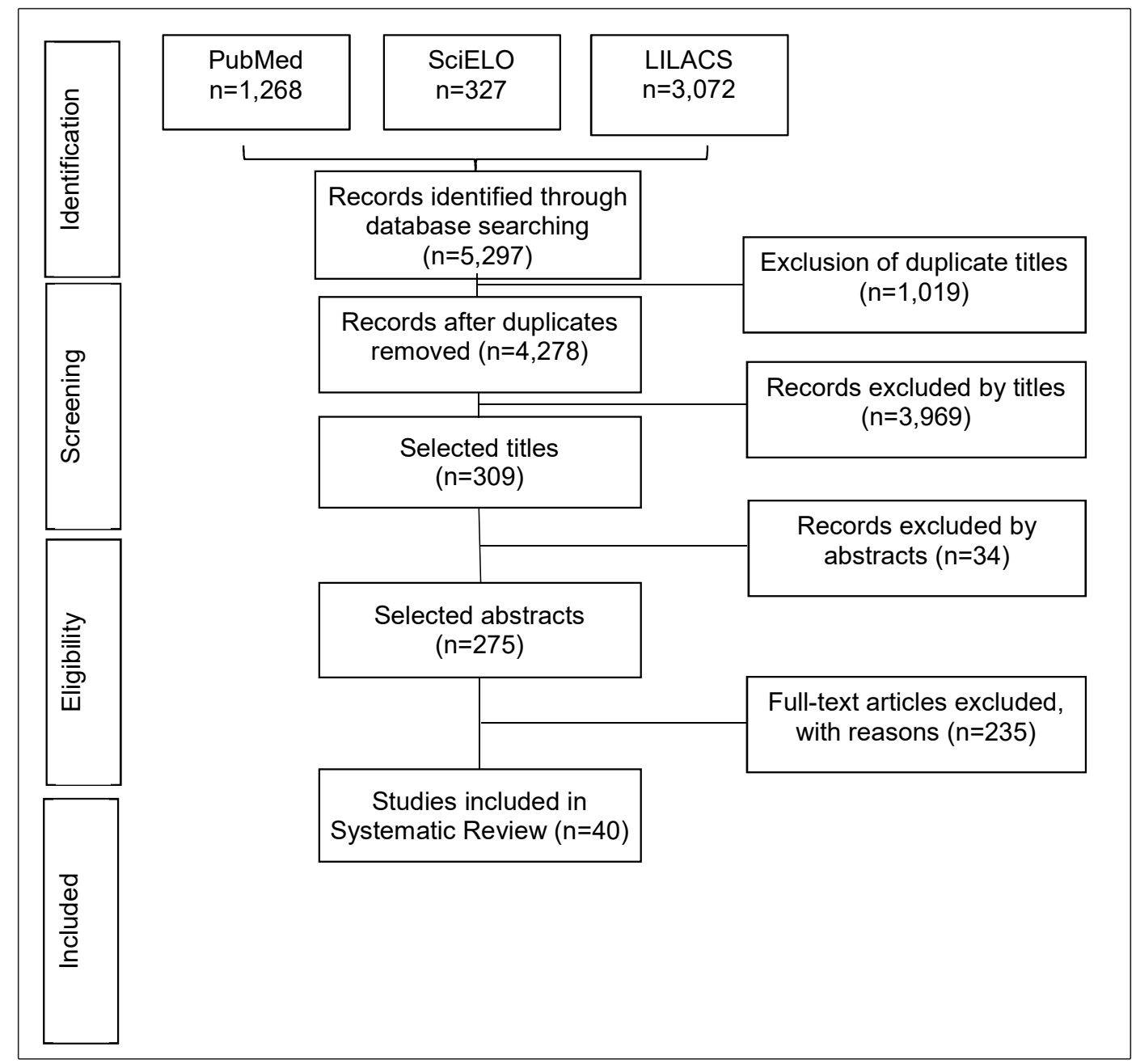

FIGURE 1: Flow diagram of study search and selection process. Abbreviations: LILACS: Literatura Latino-Americana e do Caribe em Ciências da Saúde; PubMed: MEDLINE (Medical Literature Analysis and Retrieval System Online); SciELO: Scientific Electronic Library Online.

about population characteristics: daycare children (five studies), schoolchildren (five studies), indigenous people (one study), quilombolas (one study), rural areas (one study), orphans (one study), settlement children (one study), and children from a Family Health Program area (one study). Among the eight studies that evaluated individuals over 18 years old, six had additional information about the sample population: food handlers (two studies), waste collectors (two studies), prisoners (one study), and cancer patients (one study).

The meta-analysis of the proportions included in all selected studies showed a prevalence of intestinal parasitic infections of $46 \%$ (CI: 39\%-54\%) for all of Brazil, regardless of age, with heterogeneity of $99 \%$. Evaluating data by region, we observed a percentage variation from $37 \%$ in the Southeast region to $58 \%$ in the North region (Figure 2). Considering studies performed in children and adolescents (individuals under 18 years of age), the meta-analysis identified a prevalence of $48 \%$ (CI: $40 \%-58 \%$ ) with $99 \%$ heterogeneity. In the analysis by region, the prevalence varied from $37 \%$ in the Southeast to $65 \%$ in the South and Central-West regions (Figure 3).

\section{DISCUSSION}

The WHO recommends prophylactic administration of antihelminthic drugs for at-risk population groups, including children aged 5-14 years, living in areas with a high prevalence of soiltransmitted helminthic infections ${ }^{4}$. Although there are public policies in place in Brazil to put this recommendation into practice, there is a lack of consistent data on the prevalence of intestinal parasitic infections.

In our review, most studies (32/40) evaluated the parasitic infection prevalence in children and adolescents. The behavioral and social practices of this age group may explain the higher occurrence of intestinal parasitic infections and puts 5-14-year-olds into the at-risk group. This highlights the importance of controlling parasitic infections in this population to avoid possible complications, including delayed physical and cognitive development, impaired school performance, anemia, and intestinal obstruction, which could be prevented with prophylactic anthelmintic drugs, as recommended by the $\mathrm{WHO}^{2,8,14-17}$. 
TABLE 2. Prevalence of intestinal parasitic infections in selected Brazilian studies according to author, year of publication, region and state, prevalence, and age group

\begin{tabular}{|c|c|c|c|c|c|}
\hline Region & Study & Year & State/Region & N/prevalence (\%) & Age range \\
\hline \multirow{3}{*}{ CENTRAL-WEST } & SANTOS et al. & 2014 & DF & $193 / 66.70$ & Under 18 years \\
\hline & CURVAL et al. & 2017 & $\mathrm{CO}$ & $510 / 20.19$ & Older than 18 years \\
\hline & JUNIOR et al. & 2017 & MS & $66 / 43.93$ & Older than 18 years \\
\hline \multirow{6}{*}{ NORTH } & ORLANDI et al. & 2006 & $\mathrm{RO}$ & $470 / 18.20$ & Under 18 years \\
\hline & MONTEIRO et al. & 2009 & AM & $221 / 66.40$ & Under 18 years \\
\hline & SILVA et al. & 2009 & AM & $123 / 74.25$ & Under 18 years \\
\hline & ESCOBAR et al. & 2010 & $A M$ & $245 / 82.44$ & Under 18 years \\
\hline & FONSECA et al. & 2010 & $\mathrm{~N}$ & $1133 / 38.48$ & Under 18 years \\
\hline & BANHOS et al. & 2017 & PA & $367 / 67.57$ & Under 18 years \\
\hline \multirow{12}{*}{ NORTHEAST } & GUIMARÃES et al. & 2006 & BA & $268 / 30.22$ & Under 18 years \\
\hline & BARBOSA et al. & 2006 & PB & $11234 / 45.40$ & Under 18 years \\
\hline & SANTOS et al. & 2006 & BA & $410 / 70.73$ & Under 18 years \\
\hline & CABRAL et al. & 2010 & BA & $348 / 79.31$ & Under 18 years \\
\hline & PALMEIRA et al. & 2010 & $\mathrm{AL}$ & $481 / 35.75$ & Under 18 years \\
\hline & FONSECA et al. & 2010 & NE & $1135 / 46.64$ & Under 18 years \\
\hline & FURTADO et al. & 2011 & $\mathrm{PI}$ & $294 / 40.50$ & Older than 18 years \\
\hline & SILVA et al. & 2011 & MA & $220 / 53.60$ & Under 18 years \\
\hline & CAMPOS et al. & 2011 & $\mathrm{RN}$ & $86 / 72.09$ & Under 18 years \\
\hline & souZA et al. & 2012 & $\mathrm{PE}$ & $110 / 48.18$ & Under 18 years \\
\hline & FERNANDES et al. & 2014 & $\mathrm{PI}$ & $251 / 51.39$ & Older than 18 years \\
\hline & SANTOS et al. & 2017 & $\mathrm{BA}$ & $265 / 27.16$ & Older than 18 years \\
\hline \multirow{7}{*}{ SOUTH } & QUADROS et al. & 2004 & SC & $200 / 70.05$ & Under 18 years \\
\hline & MARRONE et al. & 2004 & RS & $96 / 82.29$ & Under 18 years \\
\hline & BENCKE et al. & 2006 & RS & $222 / 45.94$ & Under 18 years \\
\hline & SANTOS et al. & 2014 & SC & $57 / 61.40$ & Under 18 years \\
\hline & COLLI et al. & 2014 & PR & $150 / 28.00$ & Older than 18 years \\
\hline & SILVA et al. & 2017 & RS & $30 / 12.00$ & Older than 18 years \\
\hline & JESKE et al. & 2017 & RS & $73 / 61.64$ & Older than 18 years \\
\hline \multirow{13}{*}{ SOUTHEAST } & CARVALHO et al. & 2002 & MG & $18973 / 18.06$ & Under 18 years \\
\hline & FERREIRA et al. & 2003 & MG & $72 / 59.72$ & Under 18 years \\
\hline & FERREIRA et al. & 2005 & $\mathrm{SP}$ & $902 / 11.50$ & Under 18 years \\
\hline & CARVALHO et al. & 2006 & SP & $279 / 53.40$ & Under 18 years \\
\hline & MENEZES et al. & 2008 & MG & $472 / 24.57$ & Under 18 years \\
\hline & BARÇANTE et al. & 2008 & MG & $176 / 22.72$ & Under 18 years \\
\hline & KORKES et al. & 2009 & SP & $120 / 30.83$ & Under 18 years \\
\hline & TASHIMA et al. & 2009 & SP & $1000 / 21.30$ & Under 18 years \\
\hline & SILVA et al. & 2010 & MG & $161 / 72.67$ & Under 18 years \\
\hline & GONÇALVES et al. & 2011 & MG & $133 / 29.32$ & Under 18 years \\
\hline & SANTOS et al. & 2012 & SE & $245 / 51.80$ & Under 18 years \\
\hline & BELO et al. & 2012 & MG & $1172 / 28.58$ & Under 18 years \\
\hline & FONSECA et al. & 2017 & SP & $233 / 57.50$ & Under 18 years \\
\hline
\end{tabular}

Abbreviations: AL: Alagoas; AM: Amazonas; BA: Bahia; CO: Central-West ; DF: Distrito Federal; MA: Maranhão; MG: Minas Gerais; MS: Mato Grosso do Sul; N: North ; NE: Northeast ; PA: Pará; PB: Paraíba; PE: Pernambuco, PI: Piauí; PR: Paraná; RO: Rondônia; RN: Rio Grande do Norte; RS: Rio Grande do Sul; SC: Santa Catarina; SE: Sergipe; SP: São Paulo.

In general, the observed prevalence of intestinal parasitic infections in our study showed high rates of heterogeneity (>90\%) by region. Differences between regions may be explained by the size of the region and the socioeconomic and historical structural disparities that may have affected the prevalence of intestinal parasitic infections $s^{1,14,18,19}$. Data from the Brazilian $\mathrm{MOH}$ obtained by active screening for infected people from 2005 to 2016 demonstrated a prevalence of soil-transmitted helminthic infections by region similar to that observed in our study ${ }^{20}$. The results from the Northeast (53\%), North (58\%), Central-West (65\%), and South $(65 \%)$ regions indicated that $50 \%$ of intestinal parasitic infections were in children and adolescents, with CIs of $42 \%-65 \%, 38-76 \%$,
$60 \%-69 \%$, and $51 \%-78 \%$, respectively. The high prevalence in the North may result from indigenous habits (hunting, fishing, farming), as most of the samples analyzed in this region belonged to this group. The high prevalence in other regions may be explained by the disorderly growth of some cities, with consequent inadequate basic sanitation, a low human development index, a reduction in quality of life, and poor health care and education, which favors the transmission of diseases, including intestinal parasitosis ${ }^{13}$.

In the Central-West region, only one study was identified. The sample comprised children and adolescents aged 4-14 years and an intestinal parasitic infection prevalence of $65 \%$ was reported. 


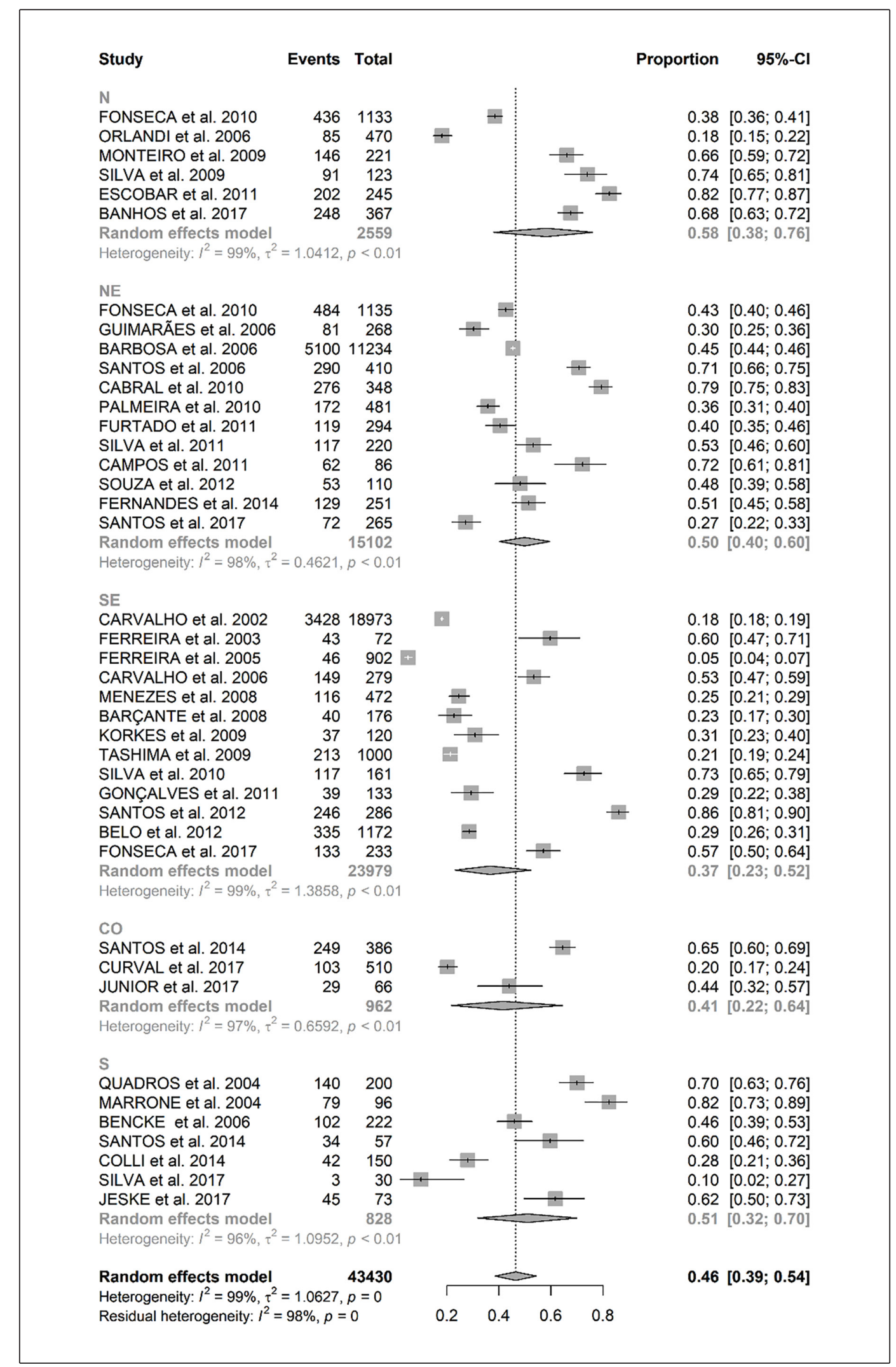

FIGURE 2: Meta-analysis of proportions of intestinal parasitic infection prevalence by Brazilian region and age groups. Abbreviations: Cl: confidence interval; CO: Central-West region ; N: North region; NE: Northeast region; S: South region; SE: Southeast region. 


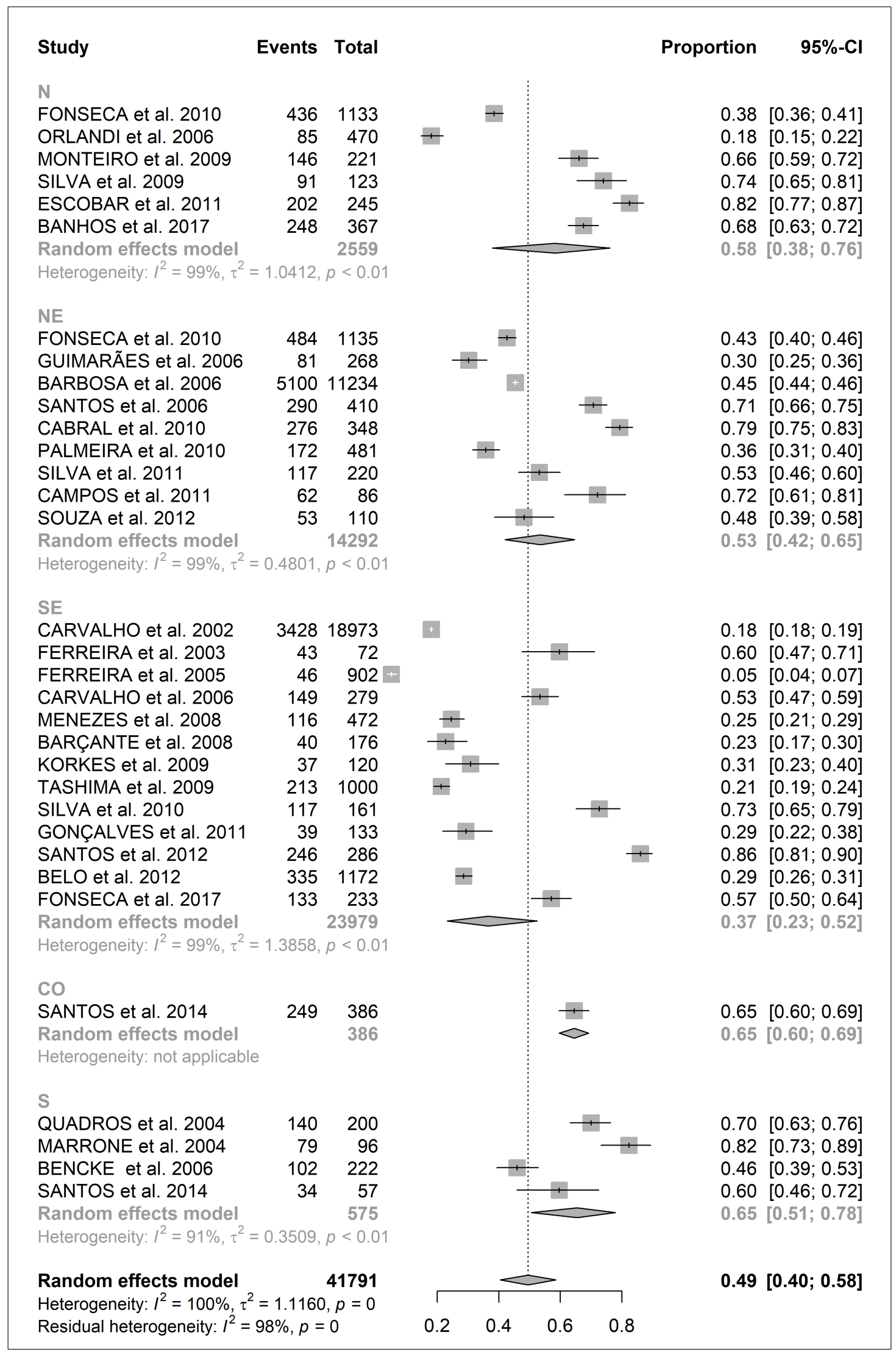

FIGURE 3. Meta-analysis of proportions of intestinal parasitic infection prevalence among children and adolescents in Brazil. Abbreviations: Cl: confidence interval; CO: Central-West region ; N: North region; NE: Northeast region; S: South region; SE: Southeast region. 
In the South, we observed variations in prevalence data among the different studies. Marrone (2004) reported a high prevalence (82\%) in children under five years of age, which far exceeded the average for the region ${ }^{21}$. Bencke (2006) reported a prevalence of $46 \%$ in public school students, and Santos (2014) described an intestinal parasitic infection prevalence of $60 \%$ among children from daycare centers aged 2-6 years ${ }^{21-24}$. There is an increased risk of transmission in environments where children are gathered together, such as in schools ${ }^{24}$.

In this systematic review, nine studies were conducted in the Northeast region. A meta-analysis of the proportions of general intestinal parasitic infections revealed a prevalence in this region of 53\% (CI: $42 \%-65 \%$ ), and most studies (4/9) reported a prevalence of more than $50 \%$. High heterogeneity $(99 \%)$ was also observed. This finding may be attributed to the characteristics of the studied population, which comprised schoolchildren, residents of quilombos, institutionalized children, and individuals from specific communities, rather than samples from the general population ${ }^{8,13,25}$.

In the Southeast, a meta-analysis of 13 studies showed a prevalence of $35 \%$ (CI: $24 \%-47 \%$ ). Most studies did not describe the group characteristics. Ferreira (2003), Carvalho (2006), Silva (2010), Santos (2012), and Fonseca (2017) reported intestinal parasitic infection prevalence of $60 \%, 53 \%, 73 \%, 86 \%$, and $57 \%$, respectively ${ }^{13,25,26,27,28}$. These studies were performed with individuals from daycare centers and settlements, where exposure to intestinal parasitic infections was more frequent ${ }^{26,27,28}$.

Our study is the first in Brazil to assess the prevalence of intestinal parasitic infections in different regions of the country by performing a meta-analysis of the proportions. It provides important data from 2000 to 2018, which may help in the conception and execution of public policies. We evaluated data from studies whose samples comprised specific populations rather than general population samples, as most of the studies focused on at-risk groups; therefore, data from the general population are limited and have not been published. The heterogeneity of these studies is also a limitation of our study, as it is likely that our calculations overestimated the prevalence of this condition. We highlight that the selected studies reflect the reality of the specific communities that need the most prominent consideration in public health actions, such as the prophylactic administration of anthelmintic drugs. Furthermore, the most commonly used test in the selected studies was the Hoffman method, which is not appropriate for diagnosing parasitic infections that may be not recognized and are not successfully treated with deworming program drugs. However, data from the Brazilian $\mathrm{MOH}$, obtained by active screening from 2005 to 2016, showed a similar distribution by region and reinforces our findings ${ }^{20}$. Another limitation is the lack of studies from the CentralWest region, with only one being included, making it impossible to properly evaluate the target age group (5-14 years) in this region with respect to the intervention proposed by the WHO. However, this single study did describe Brazilian children and adolescents of an almost identical age range, and therefore, provides some data representative of this group.

Data from this meta-analysis may not accurately reflect the prevalence of helminths, as it is biased in that it describes data from papers reporting the presence of these parasites, while negative data is often not published. However, we extensively revised the available data so that it can support important decision making in clinical practice and help create public policies that focus on parasitic infection control even with recognized bias.

Katz (2015) performed a survey to assess the prevalence of schistosomiasis and other intestinal parasitic infections (ancylostomiasis, ascariasis, and trichuriasis) among 197,564 Brazilian school children aged $7-17$ years, and reported a prevalence of $0.99 \%$ for schistosomiasis, $2.73 \%$ for ancylostomiasis, $6 \%$ for ascariasis, $5.41 \%$ for trichuriasis, and a global prevalence of $15.13 \%$ for all parasitic infections ${ }^{29}$. The study considered negative tests and found a lower global prevalence in comparison with our study; however, Katz did not evaluate all parasites and used the Kato-Katz method, which may have impaired the sensitivity of screening for helminths (other than the S. mansoni) ${ }^{29}$.

With respect to parasitic infections, non-governmental organizations, academic institutions, and governments often follow the WHO recommendations for health education activities and periodic mass administration of prophylactic anti-helminthic drugs to at-risk groups living in areas with high prevalence of soil-transmitted helminthic infections. According to the intestinal parasitic infection prevalence rates identified in this review, biannual prophylactic administration of anthelmintic drugs for at-risk groups throughout Brazil is indicated, except in the Southeast region, where annual administration for children and adolescents aged 5-14 years would be sufficient. However, a more effective long-term solution to this problem requires actions that focus on supplying clean drinking water; better sanitation, urban cleaning, and solid waste management; and improved drainage and management of urban rainwater. In the meantime, this deworming strategy needs to be continued in Brazil, especially considering that a significant percentage of the Brazilian population still lives without access to clean water $(16.4 \%)$ and without sewage collection $(46.9 \%)$ as reported by the Sanitation Panel Brazil in $2018^{30}$. The importance of making progress on these socioenvironmental issues is reinforced by the rate of hospitalization for waterborne diseases, which has reached approximately 233,880 hospital admissions per year throughout Brazil $1^{1,4,14,18,20,30,31}$. In fact, the high prevalence of parasitic intestinal infections shown in this study highlights the need for improvements in the living conditions of the general population.

It should be highlighted that the clinical benefits of deworming interventions have recently been questioned. A systematic review evaluated their effects on nutritional status, hemoglobin level, cognition, school performance, and survival, but found no evidence of improvement in these indicators ${ }^{32}$. The studies included in that review were from Africa, Asia, and Central America, but none from South America ${ }^{32}$. Our review shows that there is a high prevalence of parasitic infections in Brazil, yet there are no data on the outcomes of deworming interventions.

In conclusion, according to published studies, the prevalence of intestinal parasitic infections in Brazil is high in all five regions of the country, especially in the at-risk populations. The levels of infection found indicate that the country should follow the WHO recommendations for annual or biannual mass administration of 
prophylactic anthelmintic drugs for children and adolescents aged 5-14 years, depending on the region in which they live. However, further studies evaluating the clinical outcomes of deworming interventions in Brazil are necessary to act as a basis for decisionmaking on public policies focused on parasitic infection control. The long-term aim should be to improve a range of socioenvironmental factors to provide a lasting solution to this problem.

\section{ACKNOWLEDGEMENTS}

To all authors.

\section{AUTHORS' CONTRIBUTION}

AOC: Conception and design of the study, Acquisition of data; Conception and design of the study, Analysis and interpretation of data, Final approval of the version to be submitted; Conception and design of the study. SCFV: Conception and design of the study, Acquisition of data; Conception and design of the study, Analysis and interpretation of data, Final approval of the version to be submitted; Conception and design of the study. PASL: Acquisition of data; Conception and design of the study. LMCLR: Acquisition of data; Conception and design of the study. IRSL: Acquisition of data; Conception and design of the study. CMF: Acquisition of data; Conception and design of the study. ID de CB: Conception and design of the study, Acquisition of data; Conception and design of the study, Analysis and interpretation of data, Final approval of the version to be submitted; Conception and design of the study. RQG: Conception and design of the study, Acquisition of data; Conception and design of the study, Analysis and interpretation of data, Final approval of the version to be submitted; Conception and design of the study.

\section{CONFLICT OF INTEREST}

The authors have no conflict of interest to declare about this study.

\section{FINANCIAL SUPPORT}

There was no funding for this project.

\section{ORCID}

Ariel Oliveira Celestino: 0000-0003-3907-187X

Sarah Cristina Fontes Vieira: 0000-0002-0830-9657

Pablo Amercio Silva Lima: 0000-0002-9612-7000

Larissa Maria Cardoso Lima Rodrigues: 0000-0003-2781-2298

Isabel Ribeiro Santana Lopes: 0000-0002-0169-1101

Camila Mendonça França: 0000-0001-7839-1599

Ikaro Daniel de Carvalho Barreto: 0000-0001-7253-806X

Ricardo Queiroz Gurgel: 0000-0001-9651-3713

\section{REFERENCES}

1. Bockarie MJ, Kelly-Hope LA, Rebollo M, Molyneux DH. Preventive chemotherapy as a strategy for elimination of neglected tropical parasitic diseases: endgame challenges. Philos Trans R Soc Lond B Biol Sci. 2013; 368(1623):20120144.

2. Garg NJ. Global health: neglected diseases and access to medicines. Infect Dis Clin North Am. 2011;25(3):639-51.

3. Ohta N. Endemic tropical diseases: contemporary health problem due to abandoned diseases in the developing word. Kansenshogaku Zasshi. 2006; 80(5):469-74.

4. World Health Organization (WHO). Preventive chemotherapy in human helminthiasis: coordinated use of anthelminthic drugs in control interventions. A manual for health professionals and programme managers [Internet]. Geneva, 2006. Available from: https://www.who. int/intestinal_worms/more/en/

5. dos Santos J, Duarte ARM, Godattie G, Lima LM. Intestinal parasites in children from a community daycare center in Florianópolis, SC, Brazil. Rev Patol Trop. 2014; 43(3):332-40.

6. Croke K, Hicks JH, Hsu E, Kremer M, Miguel E. Should the WHO withdraw support for mass deworming? PLoS Negl Trop Dis. 2017;11(6): e0005481.

7. Banhos EF, Rocha JAM, Pimentel ML, Batista ETM, Silva LM. Prevalence and risk factors for intestinal parasite infections in schoolchildren in the city of Santarém, State of Pará, Brazil. ABCS Health Sci. 2017;42(3):137-42.

8. Monteiro AMC, Silva EF, Almeida KS, Sousa JJN, Mathias LA, Baptista F, et al. Parasitoses intestinais em crianças de creches públicas localizadas em bairros periféricos do município de Coari, Amazonas, Brasil. Rev Patol Trop. 2009;38(4):284-90.

9. Cabral-Miranda G, Dattoli VCC, Dias-Lima A. Enteroparasites and socioeconomic and sanitary conditions in a quilombola community in the semi-arid region of Bahia. Rev Patol Trop. 2010;39(1):48-55.

10. Mascarini LM, Donalísio MR. Giardiasis and cryptosporidiosis in institutionalized children in daycare centers in the State of São Paulo. Rev Soc Bras Med Trop. 2006; 39(6):577-9.

11. Damázio SM, Lima MS, Soares AR, Souza MAA. Intestinal parasites in a quilombola community of the Northern State of Espírito Santo, Brazil. Rev Inst Med Trop. 2013;55(3):178-83.

12. Orlandi PP, Magalhães GF, Matos NB, Silva T, Penatti M, Nogueira $\mathrm{PA}$, et al. Etiology of diarrheal infections in children of Porto Velho (Rondonia, Western Amazon region, Brazil). Braz J Med Biol Res. 2006;39(4):507-17.

13. Fonseca EOL, Texeira MG, Barreto ML, Carmo EH, Costa MCN. Prevalence and factors associated with geohelminth infections in children living in municipalities with low HDI in North and Northeast Brazil. Cad Saúde Pública. 2010: 26(1):143-52.

14. Vasquez-garibay EM, Barrera LRC, Velarde ER, Ríos LM, Cosío MEN, Rodríguez FN. Risk factors associated with iron depletion and parasites in preschool and school children of Arandas, Jalisco, México. Nutr. Hosp. 2014; 31(1):244-50.

15. Palmeirim MS, Ouattara M, Essé C, Koffi VA, Assaré RK, Hürlimann E, et al. Are schoolchildren less infected if they have good knowledge about parasitic worms? A case study from rural Côte d'Ivoire. BMC Public Health. 2018;18(1):951.

16. Mosawi SH, Dalimi A, Charkhi MA, Baarae O, Darman A, Mosavi M, et al. Gallbladder Perforation Due to Ascaris lumbricoides in a Pregnant Woman and 6 Year Old Girl from Afghanistan: Case Report. Iran J Parasitol. 2019;14(3):477-81. 
17. Chahine E, Baghdady R, Chahine C, Doghman G, El Kary N, El Khoury $\mathrm{L}$, et al. Complete resolution of obstructive colonic amebic pseudotumor with conservative treatment: A case report and literature review. Int J Surg Case Rep. 2019;59:1-3.

18. Adriko M, Tinkitina B, Arinaitwe M, Kabatereine NB, Nanyunja M, M Tukahebwa E. Impact of a national deworming campaign on the prevalence of soil-transmitted helminthiasis in Uganda (2004-2016): Implications for national control programs. PLoS Negl Trop Dis. 2018;12(7):e0006520.

19. Rodrigues C, Ziegelmann P. Meta-analysis: a practical guide. 2010. Rev HCPA. 2010;30(4):436-447.

20. Ministry of health $(\mathrm{MH})$. Practical guide for the control of Geohelminthiasis. Secretariat of Health Surveillance. [Internet]. Department of Surveillance of Communicable Diseases. Brasília; 2018. Available from: http://bvsms.saude.gov.br/bvs/publicacoes/guia_pratico_controle geohelmintiases.pdf

21. Marrone FB, Carneiro JA, Reis C, Cardozo CM, Ubal C, Carli GA. Study of enteroparasites infection frequency and chemotherapeutic agents used in pediatric patients in a community living in Porto Alegre, RS, Brazil. Rev Inst Med Trop. 2004;46(2):77-80.

22. Bencke A, Artuso LG, Reis RS, Barbieri NL, Rott MB. Parasitic infections in schoolchildren living on the outskirts of Porto Alegre, RS, Brazil. Journal of Tropical Pathology. 2006;35(1):31-36.

23. Santos J, Duarte AR, Gadotti G, Lima LM. Intestinal parasites in children from a community daycare center in Florianópolis, SC, Brazil. Rev Patol Trop. 2014;43(3):332-40.

24. Gurgel RQ, Cardoso GS, Silva AM, Santos LN, Oliveira RCV. Creche: ambiente expositor ou protetor nas infestações por parasitas intestinalis em Aracaju, SE. Rev Soc Bras Med Trop. 2005;38(3):267-9.
25. Santos CK, Grama DF, Limongi JE, Costa FC, Couto TR, Soares RM, et al. Epidemiological, parasitological and molecular aspects of Giardia duodenalis infection in children attending public daycare centers in southeastern Brazil. Trans R Soc Trop Med Hyg. 2012;106(8):473-9.

26. Carvalho TB, Carvalho FB, Mascarini LM. Occurence os enteroparasites in nursereies in Botucatu (state of São Paulo, Brazil) with an emphasis on Cryptosporidium sp., Giardia duodenalis and Enterobius vermicularis. Rev Inst Med Trop. 2006;48(05):269-73.

27. Ferreira P, Lima MR, Oliveira FB, Pereira MLM, Ramos LBM, Marçal MG, et al. Ocorrência de parasitas e comensais intestinais em crianças de escola localizada em assentamento de sem-terras em Campo Florido, Minas Gerais, Brasil. Rev Soc Bras Med Trop. 2003;39(1):48-55.

28. Ferreira GR, Andrade CFS. Alguns aspectos socioeconômicos relacionados a parasitoses intestinais e avaliação de uma intervenção educativa em escolares de Estiva Gerbi, SP. Rev Soc Bras Med Trop. 2005;38(5):402-5.

29. Katz N. Inquérito Nacional de Prevalência da Esquistossomose mansoni e Geo-helmintoses. Belo Horizonte.2018.

30. Brazil Sanitation Panel. Institute Brazil. Sanitation + Health [internet]. Avaliable from: https://www.painelsaneamento.org.br/ localidade/compare?id $=0$

31. Civil House (CS) Presidency of the Republic. Deputy Director for Legal Affairs. Law No. 11,445, of January 2007 [Internet]. Brasilia; 2007. Available at: http://www.planalto.gov.br/ccivil_03/ato2007-2010/2007/ lei/111445.html

32. Taylor-Robinson DC, Maavan N, Soares-Weiser K, Donegan S, Garner P. Deworming drugs for soil-transmitted intestinal worms in children: effects on nutritional indicators, haemoglobin, and school performance. Cochrane Database Syst Rev. 2015. DOI: 10.1002/14651858.CD000371. pub6. Avaiable from: https://www.cochranelibrary.com/cdsr/ doi/10.1002/14651858.CD000371.pub6/full. 